Actes de la journée d'études doctorales en histoire des techniques (8 mars 2004)

\title{
Renaud d'Enfert, L'enseignement du dessin en France : Figure humaine ou dessin géométrique (1750-1850)
}

Paris, Belin, 2003, 256 pages.

\section{Liliane Hilaire-Pérez}

\section{OpenEdition Journals}

Édition électronique

URL : http://journals.openedition.org/dht/1121

DOI : $10.4000 /$ dht. 1121

ISSN : $1775-4194$

Éditeur :

Centre d'histoire des techniques et de l'environnement du Cnam (CDHTE-Cnam), Société des élèves du CDHTE-Cnam

\section{Édition imprimée}

Date de publication : 1 décembre 2007

Pagination : 148-149

ISBN : 978-2-9530779-0-2

ISSN : 0417-8726

Référence électronique

Liliane Hilaire-Pérez, "Renaud d'Enfert, L'enseignement du dessin en France : Figure humaine ou dessin géométrique (1750-1850) », Documents pour l'histoire des techniques [En ligne], 14 | 2 e semestre 2007, mis en ligne le 03 novembre 2010, consulté le 23 septembre 2020. URL : http:// journals.openedition.org/dht/1121; DOI : https://doi.org/10.4000/dht.1121

Ce document a été généré automatiquement le 23 septembre 2020

(c) Tous droits réservés 


\section{Renaud d'Enfert, L'enseignement du dessin en France : Figure humaine ou dessin géométrique (1750-1850)}

Paris, Belin, 2003, 256 pages.

\section{Liliane Hilaire-Pérez}

\section{RÉFÉRENCE}

Renaud d'Enfert, L'enseignement du dessin en France : Figure humaine ou dessin géométrique (1750-1850), Paris, Belin, 2003, 256 pages.

\section{NOTE DE L'AUTEUR}

Compte-rendu remanié de celui paru dans la Revue historique, $\mathrm{n}^{\circ} 633$, CCCVII/1, janvier 2005, pp. 224-225.

1 Dans ce livre, Renaud d'Enfert propose une étude novatrice de l'histoire de l'enseignement du dessin en France lors de la première industrialisation. L'analyse est fine et dynamique. L'auteur montre que l'enseignement du dessin naît d'une tension entre la tradition académique de la copie de la figure humaine et l'invention du dessin géométrique sous l'impulsion des élites industrielles et administratives du XIXe siècle. Revendiquant une approche globale du dessin, il analyse chaque modèle à la lumière d'institutions, de pédagogies, de visions sociales et d'usages sociaux et professionnels du dessin dans des publics différenciés. Loin de se succéder, les deux modèles coexistent au sein d'un paysage institutionnel complexe.

2 La diversification de l'offre est restituée avec précision : foisonnement des écoles de dessin à la fin de l'Ancien Régime, intégration du dessin à l'enseignement général sous la Révolution et l'Empire (écoles centrales, lycées, écoles mutuelles, écoles primaires 
supérieures, écoles d'arts et métiers), nouvelle vague d'écoles sous la Restauration et la monarchie de Juillet destinées à un public artisanal et ouvrier.

3 C'est l'enseignement général qui innove. Alors que les écoles de dessin perpétuent l'héritage académique fondé sur la figure humaine, les écoles centrales sont le terrain d'expérimentation des théories de Lairesse et Mengs: tout objet est composé d'éléments géométriques dont la maîtrise graphique est un préalable au dessin de composition, tel l'alphabet d'une langue. Une méthode pédagogique progressive, analytique et raisonnée prend forme. On serait tenté de faire le lien avec la géométrie descriptive de Monge et le "dessin exact » né à l'initiative de savants conscients des limites du modèle académique pour dessiner avec précision les machines de la révolution industrielle.

4 Mais l'histoire de l'enseignement du dessin révèle plutôt un compromis entre les artistes et les savants, grâce au dessin linéaire, innovation pédagogique appliquée dans les écoles primaires supérieures (Loi Guizot, 1833). Dessin à main levée, « compas dans l'œil », sans instrument de tracé à la différence de la géométrie descriptive, il exprime une continuité avec le sensualisme hérité des Lumières et développé par le pédagogue Pestalozzi au début du XIXe siècle.

5 Promu par la Société pour l'instruction élémentaire et la Société d'encouragement pour l'industrie nationale, le dessin linéaire répond aux besoins de l'industrie et au désir de moraliser les classes populaires. Le manuel de Francœur (1819) atteste du rôle éducatif attribué au dessin comme outil de formation professionnelle, de maitrise des gestes et d'apprentissage des commandements. À travers le succès du manuel, plusieurs fois réédité, se lit une exacerbation de la méthode analytique, aux antipodes du dessin d'imitation. L'institution scolaire fait du dessin une discipline, dans tous les sens $d u$ terme.

6 Cette méthode n'exclut pas les contestations des polytechniciens, tenants du tracé géométrique (non sans succès), ni celles des artistes partisans de la figure humaine, modèle persistant dans les écoles de dessin et dans le secondaire. Le paysage est en demi-teintes, comme chez les Frères des écoles chrétiennes qui concilient dessin géométrique et dessin d'imitation. Les deux modèles se côtoient. Le dessin linéaire est un « enseignement pour le peuple » mais les écoles de dessin, fleurons de la tradition académique, s'adressent aussi à un public artisanal (parisien), renommé pour ses produits de qualité. La discipline «dessin » se construit donc en référence aux deux modèles.

7 La richesse de la réflexion est servie par un style clair et rigoureux. Les notes, la bibliographie, les index et les illustrations ajoutent à l'excellence de l'ouvrage.

\section{AUTEURS}

LILIANE HILAIRE-PÉREZ

CDHTE-Cnam 